\title{
Investigation of the effect of zinc precursors onto structural, optical and electrical properties of CBD deposited $\mathrm{ZnS}$ thin films
}

\author{
Rajeshkumar P Khatri ${ }^{1}$, Amitkumar J Patel ${ }^{2}$ \\ ${ }^{1}$ Department of Physics, Gujarat Technological University, Ahmedabad 382424, Gujarat, India \\ ${ }^{2}$ Department of Applied Science, Faculty of Physics, Government Engineering College, Godhra, \\ Panchmahal 389001, Gujarat, India \\ rajukhatri_222@yahoo.co.in
}

DOI 10.17586/2220-8054-2021-12-3-317-328

\begin{abstract}
Zinc sulfide $(\mathrm{ZnS})$ thin films were deposited onto microscopic silica slides through the cost-effective chemical bath deposition (CBD) method. The optimized bath parameters were: $25 \mathrm{ml}$ of $0.1 \mathrm{M}$ zinc precursors $\left(\mathrm{ZnCl}_{2}, \mathrm{Zn}\left(\mathrm{CH}_{3} \mathrm{COO}\right)_{2}, \mathrm{ZnSO}_{4}\right), 25 \mathrm{ml}$ of $1 \mathrm{M}$ thiourea and $3 \mathrm{ml}$ of $3.75 \mathrm{M}$ triethanolamine (TEA). The effects of different zinc precursors $\left(\mathrm{ZnCl}_{2}, \mathrm{Zn}\left(\mathrm{CH}_{3} \mathrm{COO}\right)_{2}, \mathrm{ZnSO}_{4}\right)$ on the growth mechanism of $\mathrm{ZnS}$ thin film were investigated using thermal, structural, morphological, optical and electrical studies. The XRD pattern has shown Miller indexing peaks corresponding to the hexagonal phase of as-grown $\mathrm{ZnS}$ thin film with the estimated grain size of $22-27 \mathrm{~nm}$. The change in physical properties (weight loss) of $\mathrm{ZnS}$ powder as a function of temperature was recorded using thermogravimetry (TGA/DTA). Scanning electron microscopy (SEM) revealed the effect of $\mathrm{ZnCl}_{2}, \mathrm{Zn}\left(\mathrm{CH}_{3} \mathrm{COO}\right)_{2}$ and $\mathrm{ZnSO}_{4}$ precursors on growth mechanism. UV/visible optical transmission/absorption spectra displayed the transmittance between 10 to $29 \%$ of as-grown $\mathrm{ZnS}$ thin film with a band gap in the range of $4.10-4.25 \mathrm{eV}$. Photoluminescence (PL) analyses demonstrated broad blue emission around $\sim 459 \mathrm{~nm}$ was attributed to recombination of electron-hole pair from donor-acceptor trap levels to valance band. Raman spectra of ZnS powder prepared using different zinc precursors were also reported. The values of electrical parameters (resistivity, conductivity, activation energy, Hall coefficient, carrier concentration, mobility) were investigated using the two-point probe method and Hall-effect apparatus.
\end{abstract}

Keywords: ZnS thin films, chemical bath deposition, zinc precursors.

Received: 20 January 2021

Revised: 22 April 2021

Final revision: 26 May 2021

\section{Introduction}

Zinc sulfide $(\mathrm{ZnS})$ is the most promising material in the field of sensors [1], solar cell [2] and bio-imaging [3]. It is a wide band gap semiconductor that serves as host materials for various kinds of dopant for luminescence application [4]. In view of the above technological importance, several researchers have made efforts to tailor the physical properties of $\mathrm{ZnS}$ thin films using variation in thickness [5], molar concentration [6], heat treatment [7], bath temperature [8] and other possible means. Earlier, M. Cao, et al. [9] and T. Liu, et al. [10] investigated the effect of different zinc salts on crystallographic, morphology and optical properties of CBD deposited ZnS thin films. In earlier reported literatures, there has not been enough investigation with the effect of zinc precursors on the physical properties of $\mathrm{ZnS}$ thin films.

$\mathrm{ZnS}$ thin film has been developed by various researchers using different chemical and physical deposition methods such as Thermal evaporation [11], Metal-organic chemical vapor deposition (MOCVD) [12], Successive ionic layer adsorption and reaction (SILAR) [13], Chemical bath deposition [14], etc. Among these deposition methods, CBD is simple, cost-effective and ideal for large scale deposition [15]. Using this CBD method, a thin film can be deposited nearly at room temperature through a controlled chemical reaction.

In the present work, authors have tried to deposit CBD-ZnS thin film using triethanolamine (TEA) as a complexing agent since it is a much safer alternative compare to hydrazine hydrate [16]. Moreover, the researchers have investigated the effect of different zinc precursors $\left(\mathrm{ZnCl}_{2}, \mathrm{Zn}\left(\mathrm{CH}_{3} \mathrm{COO}\right)_{2}, \mathrm{ZnSO}_{4}\right)$ on structural, morphological, optical and electrical properties of CBD deposited $\mathrm{ZnS}$ thin films. 


\section{Experimental method}

All reagents were received from Fisher Scientific and used without further processing. A high-quality silica slide having dimensions $75 \times 26 \times 1 \mathrm{~mm}^{3}$ is used as substrate. The cleaning procedure and detailed process of film deposition are reported in our earlier literature [17]. The only difference in the present work is that we deposited three different samples using three different precursors instead of zinc chloride, as reported in earlier work. The optimized molar concentration and volume of precursors for the growth of $\mathrm{ZnS}$ thin films are listed in Table 1. The pre-cleaned silica substrate is inserted vertically into the reaction bath. The bath temperature was adjusted to $70{ }^{\circ} \mathrm{C}$ and deposition was carried for 2 hours. The simplified layout of the chemical bath deposition method is represented in Fig. 1.

TABLE 1. Molar concentration and volume of precursors for the growth of $\mathrm{ZnS}$ thin films by CBD method

\begin{tabular}{ccccc}
\hline \multirow{2}{*}{ Thin film } & \multicolumn{4}{c}{ Molar concentration and volume of precursors } \\
\cline { 2 - 5 } & zinc precursor & thiourea & Triethanolamine (TEA) & Ammonia \\
\hline \hline $\mathrm{ZnS}-\mathrm{Cl}$ & $25 \mathrm{ml}$ of $0.1 \mathrm{M} \mathrm{ZnCl}_{2}$ & $25 \mathrm{ml}$ of $1 \mathrm{M}$ & $3 \mathrm{ml}$ of $3.75 \mathrm{M}$ & $2 \mathrm{ml}$ of $13.4 \mathrm{M}$ \\
\hline $\mathrm{ZnS}-\mathrm{Ac}$ & $25 \mathrm{ml}$ of $0.1 \mathrm{M} \mathrm{Zn}\left(\mathrm{CH}_{3} \mathrm{COO}\right)_{2}$ & $25 \mathrm{ml}$ of $1 \mathrm{M}$ & $3 \mathrm{ml}$ of $3.75 \mathrm{M}$ & $2 \mathrm{ml}$ of $13.4 \mathrm{M}$ \\
\hline $\mathrm{ZnS}-\mathrm{SO}$ & $25 \mathrm{ml}$ of $0.1 \mathrm{M} \mathrm{ZnSO}_{4}$ & $25 \mathrm{ml}$ of $1 \mathrm{M}$ & $3 \mathrm{ml}$ of $3.75 \mathrm{M}$ & $2 \mathrm{ml}$ of $13.4 \mathrm{M}$ \\
\hline
\end{tabular}

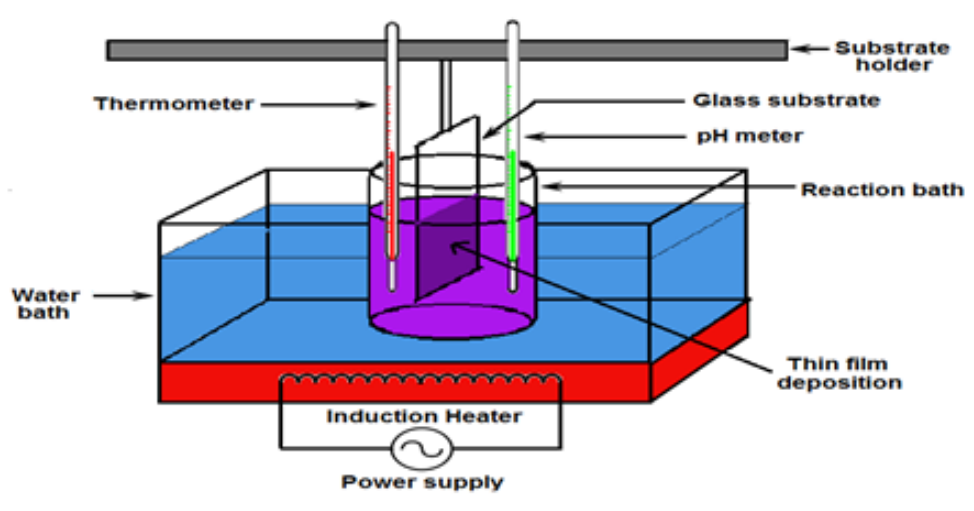

FIG. 1. Simplified layout of Chemical Bath Deposition Method

After the deposition, the film is taken out from the bath and dipped into de-ionized water to remove loosely bound $\mathrm{ZnS}$ powder that adheres to the film. $\mathrm{ZnS}$ thin films deposited using $\mathrm{ZnCl}_{2}, \mathrm{Zn}\left(\mathrm{CH}_{3} \mathrm{COO}\right)_{2}$ and $\mathrm{ZnSO}_{4}$ were labeled as $\mathrm{ZnS}-\mathrm{Cl}, \mathrm{ZnS}-\mathrm{Ac}$ and $\mathrm{ZnS}-\mathrm{SO}$, respectively for the sake of analysis.

The deposited $\mathrm{ZnS}$ thin films were analyzed using various instruments without annealing treatment. The alteration in physical properties as a function of temperature was obtained using thermogravimetry (METTLER TOLEDO). The Miller indices (h k l) for diffracting planes for the given structure of the thin film was evaluated by grazing incident $\mathrm{X}$-ray diffraction (GIXRD) spectrometer (PANalytical Empyrean) using $\mathrm{CuK} \alpha$ radiations (wavelength $=0.15406 \mathrm{~nm}$ ) for $2 \theta$ values over $20-60^{\circ}$. X-ray was impinging at angle $0.5^{\circ}$ and a detector was moving in the step of $0.01^{\circ}$ with a collection time of $7 \mathrm{~s}$. The surface morphology was characterized using the field emission scanning electron microscope (JEOL JSM-6010LA). The stoichiometric composition of films was analyzed by energy dispersive Xray analysis (EDX) using an EDX detector which is available as an add-on attachment with the scanning electron microscope (JEOL JSM-5610LV) with Inca software. In order to find the permitting light wavelengths for thin films, transmission/reflectance spectra were recorded as a function of wavelengths using UV/VIS/NIR spectrophotometer (Perkin Elmer Lambda 19). The Raman scattering measurement (vibrational phonon modes) was investigated at room temperature using a Raman microscope (RENISHAW Invia) with $514 \mathrm{~nm}(20 \mathrm{~mW})$ argon ion excitation source. Photoluminescence spectra were registered with Perkin Elmer spectro-fluoro-photometer using $280 \mathrm{~nm}$ excitation wavelength. A self-made two probe resistivity measurement equipment and Hall-effect apparatus were used to find the correlation between different electrical parameters. 


\section{Results and discussion}

\subsection{Thermal analysis}

In order to perform thermal analysis of the obtained samples, the as-deposited $\mathrm{ZnS}$ powders are collected by scratching the surface of deposited silica substrates. The analysis of the thermal behavior of scratched as-deposited $\mathrm{ZnS}$ powders were carried out using differential thermal analysis (DTA) and thermogravimetric analysis (TGA) in an ambient environment with temperature in the range of $30-900{ }^{\circ} \mathrm{C}$. During measurements, the temperature was increased at a rate of $30{ }^{\circ} \mathrm{C} / \mathrm{min}$. DTA and TGA curves for $\mathrm{ZnS}-\mathrm{Cl}, \mathrm{ZnS}-\mathrm{Ac}$, and $\mathrm{ZnS}-\mathrm{SO}$ powder are shown in Fig. 2.
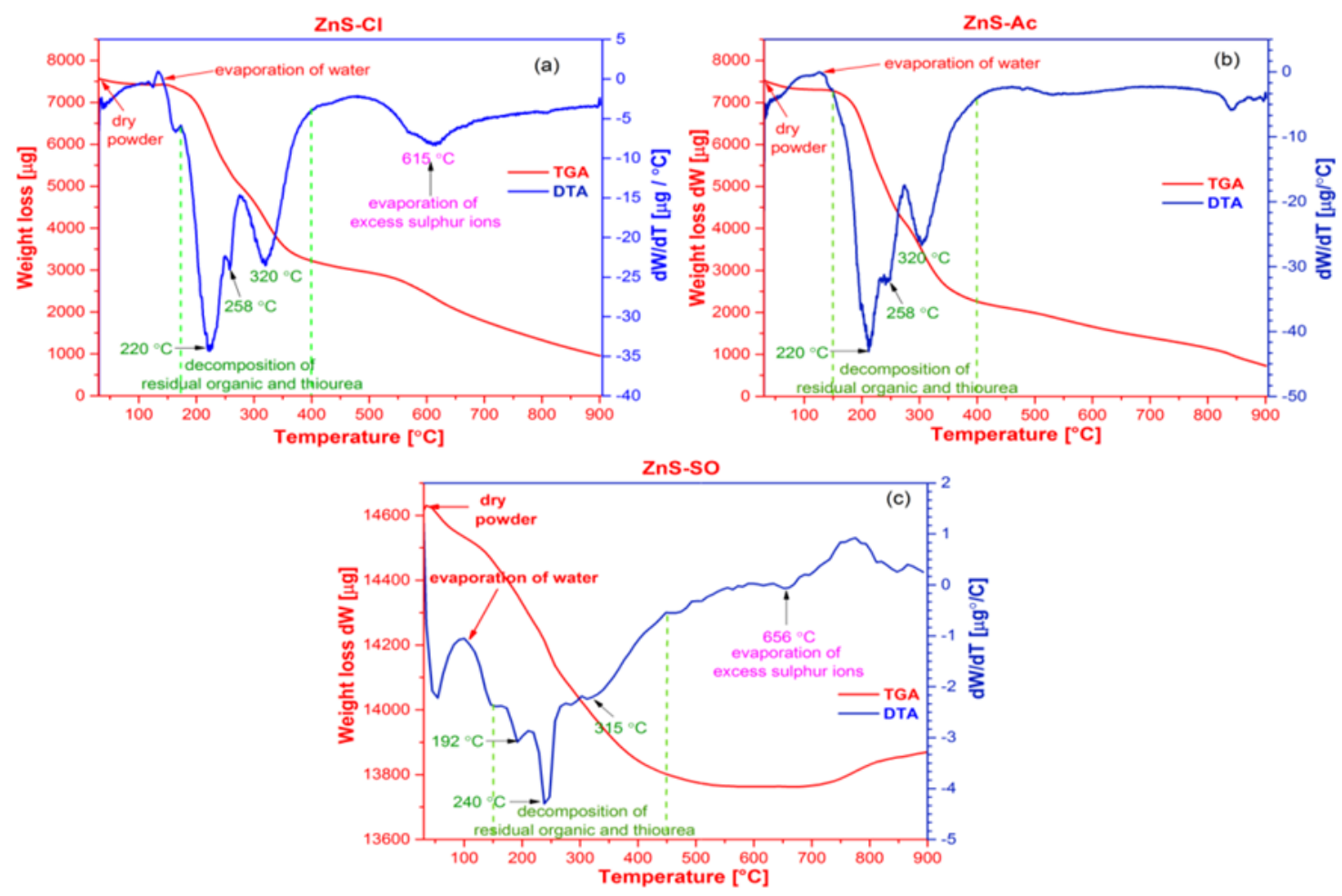

FIG. 2. TGA and DTA curves for ZnS powders grown by CBD method using different zinc precursors: (a) $\mathrm{ZnS}-\mathrm{Cl}$; (b) $\mathrm{ZnS}-\mathrm{Ac}$ (c) $\mathrm{ZnS}-\mathrm{SO}$

The TGA curve indicates that all the as-grown samples of $\mathrm{ZnS}$ lose weight from 30 to $150{ }^{\circ} \mathrm{C}$ as a result of absorbed water vapor evaporation. The decomposition of residual organics and TEA leads to second weight loss between $150-450{ }^{\circ} \mathrm{C}$. It is also confirmed by a series of endothermic peaks between temperature ranges $150-450{ }^{\circ} \mathrm{C}$ in DTA sketches, as shown in Fig. 2. The endothermic peak at $615^{\circ} \mathrm{C}$ in the case of $\mathrm{ZnS}-\mathrm{Cl}$ and $656{ }^{\circ} \mathrm{C}$ in the case of $\mathrm{ZnS}-\mathrm{SO}$ could be attributed to the evaporation of excess residual sulfur ions from the sample [18].

\subsection{Structural analysis}

The structural information of $\mathrm{ZnS}$ thin film was obtained using grazing incident X-ray diffraction (GIXRD) with $\mathrm{CuK} \alpha$ radiation with scan range $20-60^{\circ}$. GIXRD can reduce the signal contribution from the substrate and improve the signal from the thin film. X-ray diffractogram of as-grown $\mathrm{ZnS}$ thin film prepared using different zinc precursors $\left(\mathrm{ZnCl}_{2}, \mathrm{Zn}\left(\mathrm{CH}_{3} \mathrm{COO}\right)_{2}\right.$ and $\left.\mathrm{ZnSO}_{4}\right)$ are shown in Fig. 3.

The peaks at $2 \theta$ values $31.64^{\circ}, 34.53^{\circ}, 36.20^{\circ}, 47.45^{\circ}$ and $56.48^{\circ}$ are diffraction angles for planes with Miller

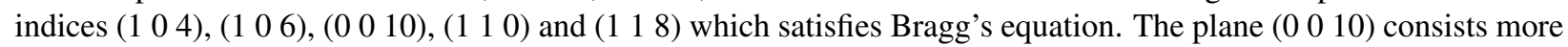
number of atoms resulted in the highest intensity peak. Comparing observed peaks with JCPDS card No. 39-1363 assures hexagonal phase of $\mathrm{ZnS}$ thin film.

The particle size of $\mathrm{ZnS}$ thin films deposited using different zinc precursors were calculated using the DebyeScherrer formula as [19]:

$$
D=\frac{0.94 \lambda}{\beta \cos \theta}
$$




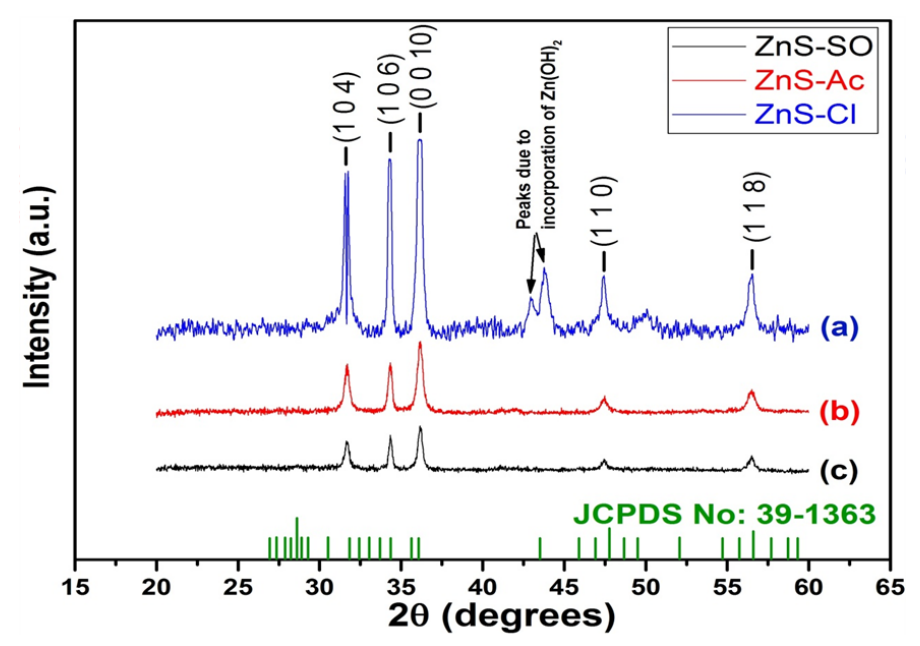

FIG. 3. X-ray diffractogram for as-grown $\mathrm{ZnS}$ thin films deposited using different zinc precursors: (a) $\mathrm{ZnS}-\mathrm{Cl}$; (b) ZnS-Ac; (c) ZnS-SO

where $D$ is particle size, $\lambda$ is the wavelength of incident X-ray generally its value is $0.15406 \mathrm{~nm}$ for CuK $\alpha$ radiation, $\beta$ is full width at half maximum (FWHM) for the peak of the plane with Miller indices (h k l) and $\theta$ is the angle between the incident beam and (h $\mathrm{k} \mathrm{l}$ ) plane. The particle sizes of as-grown $\mathrm{ZnS}$ thin film deposited using different zinc precursors onto the silica substrate are listed in Table 2. From X-ray diffractogram and particle size analysis, it is clearly observed that anions associated with zinc precursors play an important role in the growth chemistry of $\mathrm{ZnS}$ thin films. The intermolecular interactions between anions and intermediate complex precursors decide heterogeneous or homogenous growth mechanism for $\mathrm{ZnS}$ film growth [10]. In our case, the $\mathrm{Cl}^{-}$anions favor heterogeneous (ions by ions) growth mechanism and improve the crystallinity of $\mathrm{ZnS}$ thin films while $\mathrm{SO}_{4}^{-2}$ and $\mathrm{CH}_{3} \mathrm{COO}^{-}$anions follow homogeneous (clusters by clusters) or mixed growth mechanism for $\mathrm{ZnS}$ thin film formation on silica slide. Moreover, two extra peaks are observed in the case of $\mathrm{ZnS}-\mathrm{Cl}$ thin film at 42.93 and $43.87^{\circ}$, which are likely due to the incorporation of $\mathrm{Zn}(\mathrm{OH})_{2}$ into the film during the growth process [20,21]. In this case, $\mathrm{ZnS}$ film could be formed by the decomposition of thiourea over the surface of intermediate hydroxide cluster $\mathrm{Zn}(\mathrm{OH})_{2}$ rather than nucleate separately in the solution.

TABLE 2. Particle size, thickness, transmittance and band gap of as-grown $\mathrm{ZnS}$ thin films deposited using different zinc precursors

\begin{tabular}{ccccc}
\hline $\begin{array}{c}\text { Thin film } \\
(\mathbf{Z n S} \text { thin film) }\end{array}$ & $\begin{array}{c}\text { Particle size } \\
(\mathbf{n m})\end{array}$ & $\begin{array}{c}\text { Thickness } \\
(\boldsymbol{\mu} \mathbf{m})\end{array}$ & $\begin{array}{c}\text { Avearge } \\
\text { Transmittance } \\
\boldsymbol{T}(\boldsymbol{\%})\end{array}$ & $\begin{array}{c}\text { Band gap } \\
(\mathbf{e V})\end{array}$ \\
\hline \hline ZnS-Cl & 27 & $37 \pm 0.2$ & 29 & 4.10 \\
\hline ZnS-Ac & 25 & $39 \pm 0.3$ & 25 & 4.17 \\
\hline ZnS-SO & 22 & $41 \pm 0.2$ & 10 & 4.25 \\
\hline
\end{tabular}

The thickness of $\mathrm{ZnS}$ thin films deposited using different zinc precursors was predicted using the transverse view of SEM images, which are presented in Fig. 4. The observed values of thickness are listed in Table 2. It is apparently clear that the thickness of $\mathrm{ZnS}$ thin films was greatly affected by growth rate and hence liberated anions from zinc precursors in solution during growth mechanism.

In order to investigate the effect of zinc precursors onto the surface morphology of as-grown $\mathrm{ZnS}$ thin film, micrographs of films were recorded using scanning electron microscope which is shown in Fig. 5. In general, the films deposited by chemical route have uncontrolled growth rate resulted in non-uniform surface.

In the present research, $\mathrm{ZnS}$ thin films acquire rough surfaces due to uneven grain growth in different directions. Fig. 5(a) shows $\mathrm{ZnS}-\mathrm{Cl}$ film has a smooth, compact surface with reduced grain boundaries than other films. The reduction of grain boundaries has a considerable effect on the carrier drift velocity of materials [22]. Fig. 5(c) shows 

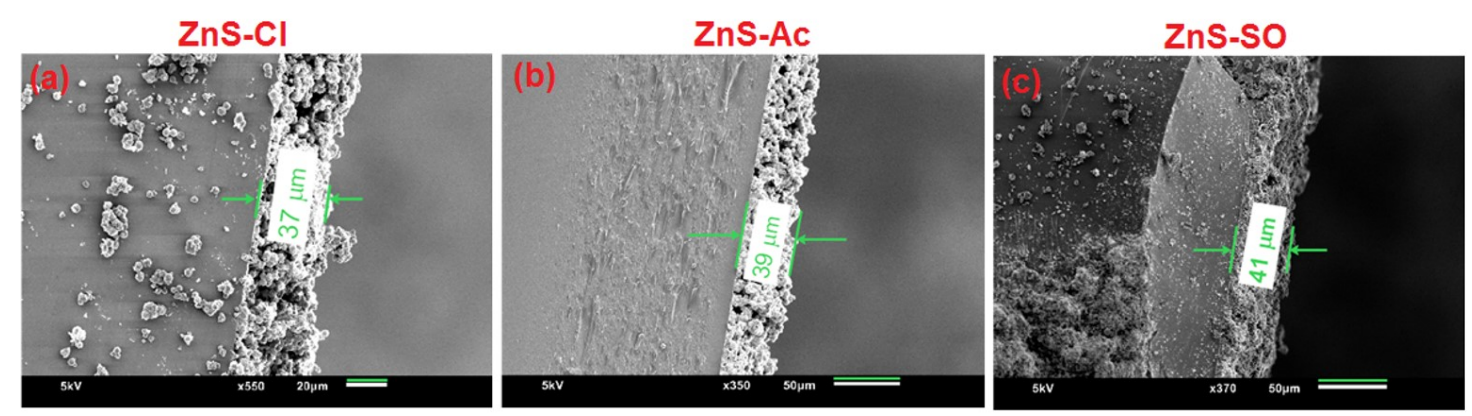

FIG. 4. Transverse view of SEM images for as-grown $\mathrm{ZnS}$ thin films deposited using different zinc precursors: (a) $\mathrm{ZnS}-\mathrm{Cl}$; (b) $\mathrm{ZnS}-\mathrm{Ac}$; (c) $\mathrm{ZnS}-\mathrm{SO}$
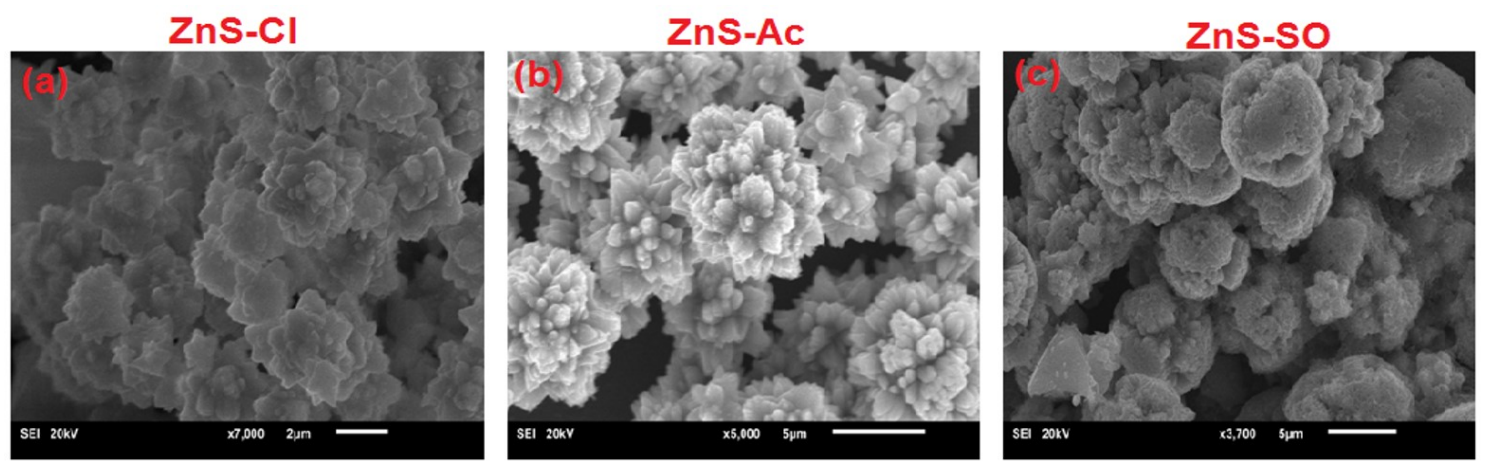

FIG. 5. SEM micrograph of as-grown $\mathrm{ZnS}$ thin films deposited using different zinc precursors: (a) $\mathrm{ZnS}-\mathrm{Cl}$; (b) ZnS-Ac; (c) ZnS-SO

$\mathrm{ZnS}-\mathrm{SO}$ films formed by significant spherical clusters with relatively less dense morphology. The reason for this is $\mathrm{SO}_{4}^{-2}$ anions promote homogeneous (clusters by clusters) growth mechanism and $\mathrm{ZnS}$ clusters from solution adhere on a silica substrate. Fig. 5(b) shows $\mathrm{ZnS}-\mathrm{Ac}$ film is relatively less compact than $\mathrm{ZnS}-\mathrm{Cl}$ with flower-like morphology. In this case, $\mathrm{CH}_{3} \mathrm{COO}^{-}$anions promote a mixed growth mechanism in the solution for deposition of $\mathrm{ZnS}$ thin films.

\subsection{Compositional analysis}

The elemental composition of $\mathrm{ZnS}$ films deposited onto the silica substrate using different zinc precursors was analyzed using EDX spectra and is shown in Fig. 6. The obtained results are listed in Table 3. Because of the low thickness of films and high depth profile of EDX spectrometer, other elements from silica substrate such as $\mathrm{O}, \mathrm{Mg}, \mathrm{Si}$, and $\mathrm{Ca}$ are also detected in the EDX spectra. As seen from Table 3, the atomic ratios of $\mathrm{Zn} / \mathrm{S}$ are slightly higher than 1 which indicates that the obtained $\mathrm{ZnS}$ films are rich in zinc and deficient in sulfur. The difference in the $\mathrm{Zn} / \mathrm{S}$ ratio is ascribed to different growth mechanisms involved during film formation. The presence of excess zinc in the case of $\mathrm{ZnS}-\mathrm{Cl}$ films could be due to the presence of $\mathrm{Zn}(\mathrm{OH})_{2}[9,10]$, which is consistent with our XRD results.

TABLE 3. Elemental composition of as-deposited $\mathrm{ZnS}$ thin films from EDX spectra

\begin{tabular}{ccccc}
\hline Thin film & Zn (at \%) & $\boldsymbol{S}($ at \%) & Other elements (at \%) & Zn/S atomic ratio \\
\hline \hline ZnS-Cl & 26.22 & 22.74 & 51.04 & 1.15 \\
\hline ZnS-Ac & 25.38 & 22.58 & 52.04 & 1.12 \\
\hline ZnS-SO & 24.71 & 22.45 & 52.84 & 1.10 \\
\hline
\end{tabular}



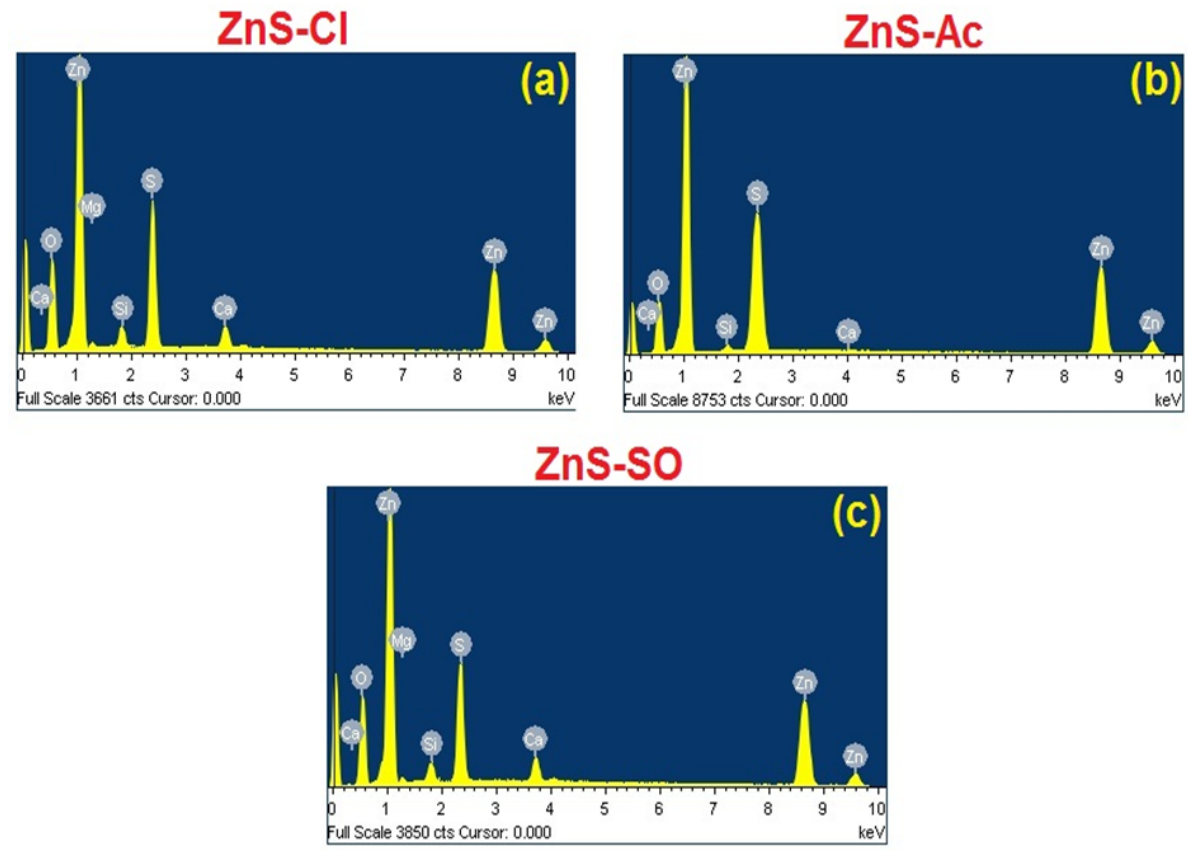

FIG. 6. EDX spectra of as-grown $\mathrm{ZnS}$ thin films deposited using different zinc precursors: (a) ZnS$\mathrm{Cl}$; (b) $\mathrm{ZnS}-\mathrm{Ac}$; (c) $\mathrm{ZnS}-\mathrm{SO}$

\subsection{Optical analysis}

The thickness and uniformity of film play a vital role in controlling optical properties like transmittance, absorbance, refractive index, etc. [23]. A film with higher uniformity and the least thickness leads to the high transmission with a sharp absorption edge [24]. Moreover, the energy band gap of the film can be determined from transmission spectra [23].

In the direction to know the effect of zinc precursors on the optical behavior of as-grown ZnS thin films, transmittance and reflectance spectra were noted using UV/VIS/NIR spectrophotometer. Fig. 7 shows the percentage of transmittance and absorbance of CBD-deposited as-grown $\mathrm{ZnS}$ thin films with zinc precursor variation. The highest transmittance is observed in $\mathrm{ZnS}-\mathrm{Cl}$ thin film and lowest in $\mathrm{ZnS}-\mathrm{SO}$ thin film. It shows low absorption above $350 \mathrm{~nm}$ wavelength and abrupt absorption at $\sim 310 \mathrm{~nm}$ wavelength for all $\mathrm{ZnS}$ thin films.

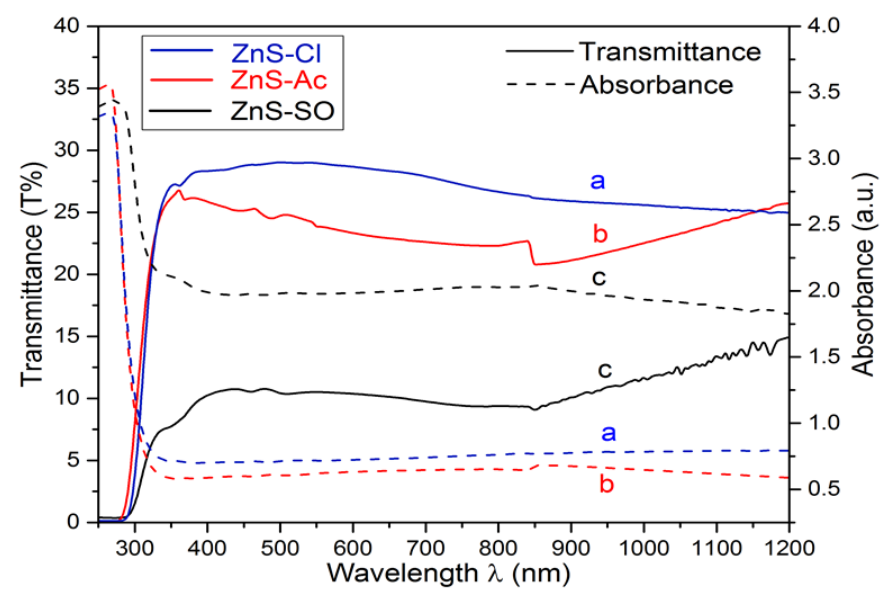

FIG. 7. UV/visible transmittance and absorbance spectra of as-grown ZnS thin films deposited using different zinc precursors: (a) $\mathrm{ZnS}-\mathrm{Cl}$; (b) $\mathrm{ZnS}-\mathrm{Ac}$; (c) $\mathrm{ZnS}-\mathrm{SO}$

Once Transmission/Reflectance data were registered with respect to wavelength, the optical energy band gaps of thin films were evaluated with the help of the formula derived from the theory of inter-band transition of the 
semiconductor. The absorption coefficient $(\alpha)$ was determined from absorbance $(A)$ and film thickness $(t)$ by using the relation $[25,26]$ :

$$
\alpha=\frac{2.303 \cdot A}{t}
$$

The theory of inter-band transition shows that at the optical absorption edge, the absorption coefficient $(\alpha)$ varies with the photon energy $\mathrm{h} \nu$ according to [23]:

$$
\alpha h \nu=A\left(h \nu-E_{g}\right)^{n},
$$

where $E_{g}$ is the optically forbidden energy gap, $A$ is constant and the exponential factor $n=1 / 2,1,2,3$ depending on the type of electronic transition in k-space [26]. For direct band gap semiconductor, the exponential factor has value 0.5 and for indirect band gap semiconductor, it has a value of 2. Since $\mathrm{ZnS}$ is a direct band gap material, the value of $n$ becomes 0.5 :

$$
(\alpha h \nu)^{2}=A^{2}\left(h \nu-E_{g}\right) .
$$

Figure 8 represents the plot of $(\alpha h \nu)^{2}$ versus $h \nu$ for as-grown $\mathrm{ZnS}$ thin film deposited from different zinc precursors. The film's band gap value is obtained by extrapolating the straight-line portion of curves to $\alpha h \nu=0$ using a computer fitting program in which the intercept value of $h \nu$-axis is band gap value. The calculated band gaps $\left(E_{g}\right)$ for as-grown $\mathrm{ZnS}$ films are listed in Table 2. The estimated band gap value of $\mathrm{ZnS}-\mathrm{Cl}, \mathrm{ZnS}-\mathrm{Ac}$ and $\mathrm{ZnS}-\mathrm{SO}$ thin films are found to be 4.10, 4.17 and $4.25 \mathrm{eV}$, respectively. The tabulated band gap values of $\mathrm{ZnS}$ thin films showed that the increase in particle size due to the presence of different anions during the growth mechanism lower the band gap values due to the quantum size effect. Further, the tabulated band gap values of all $\mathrm{ZnS}$ thin films are slightly higher than bulk $\mathrm{ZnS}$, which is probably due to the quantum size effect as the grown polycrystalline thin films' grain size is small enough [10,27].

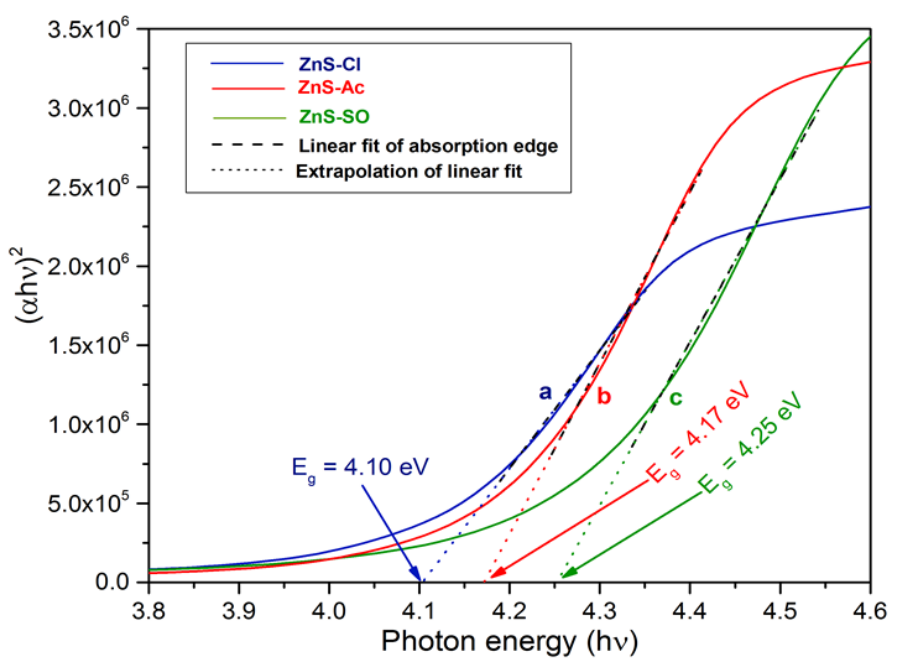

FIG. 8. Plot of $(\alpha h \nu)^{2}$ versus $h \nu$ for as-grown $\mathrm{ZnS}$ thin films deposited using different zinc precursors: (a) ZnS-Cl; (b) ZnS-Ac; (c) ZnS-SO

\subsection{Photoluminescence study}

The photoluminescence (PL) spectra of as-grown $\mathrm{ZnS}$ thin film grown using different zinc precursors under UV excitation is presented in Fig. 9. The intense emission with blue wavelength range is observed in all $\mathrm{ZnS}$ thin films, which could be attributed to the recombination of electron-hole pair from donor-acceptor trap levels to the valance band [28]. The stoichiometric difference of $\mathrm{ZnS}$ film during the growth mechanism is responsible for various kinds of defect formations. As per EDX analysis, the obtained $\mathrm{ZnS}$ films have a $\mathrm{Zn} / \mathrm{S}$ ratio greater than 1 . This stoichiometric deviation leads to excess zinc and a sulfur deficiency which could produce zinc interstitial $\left(\mathrm{Zn}_{i}\right)$ and sulfur vacancies $\left(V_{S}\right)$ in $\mathrm{ZnS}$ thin film. The broadening of PL spectra around $\mathrm{Zn}_{i}$ was ascribed to various kinds of donor-acceptor pair transitions due to the formation of native defect states into the forbidden gap, which is depicted in Fig. 10.

In the present case, blue emission at $\sim 459 \mathrm{~nm}$ signifies the involvement of interstitial zinc ions [28]. The spreading of emission spectra of $\mathrm{ZnS}$ thin film around blue wavelength is credited to different types of donor-acceptor transitions along with zinc interstitial [28]. The intensity of $\mathrm{ZnS}-\mathrm{SO}$ is higher than other films and can be ascribed to the hindrance of diffusion of zinc complex precursors onto the silica substrate during growth of film and hence the 


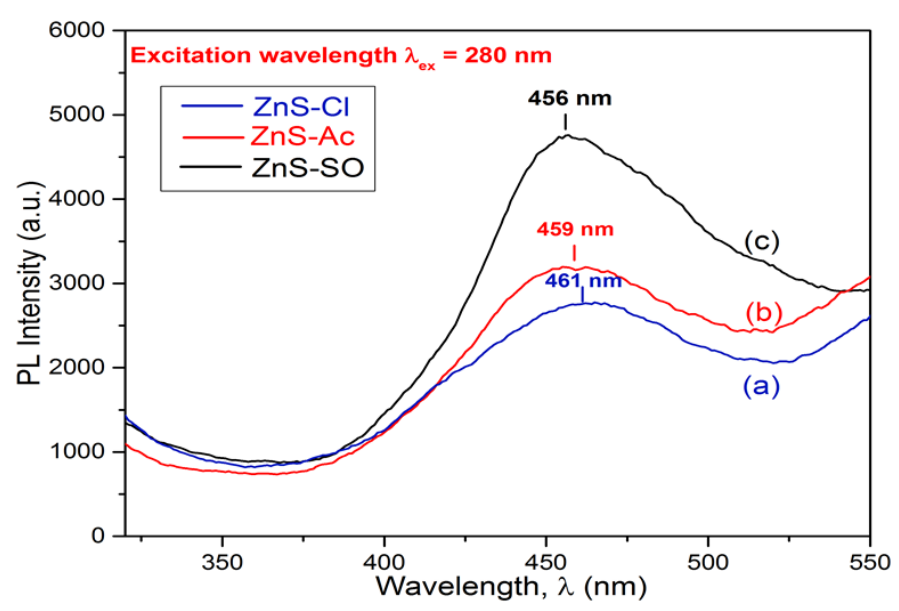

FIG. 9. Emission spectra of as-grown $\mathrm{ZnS}$ thin films deposited using different zinc precursors: (a) $\mathrm{ZnS}-\mathrm{Cl}$; (b) ZnS-Ac; (c) ZnS-SO

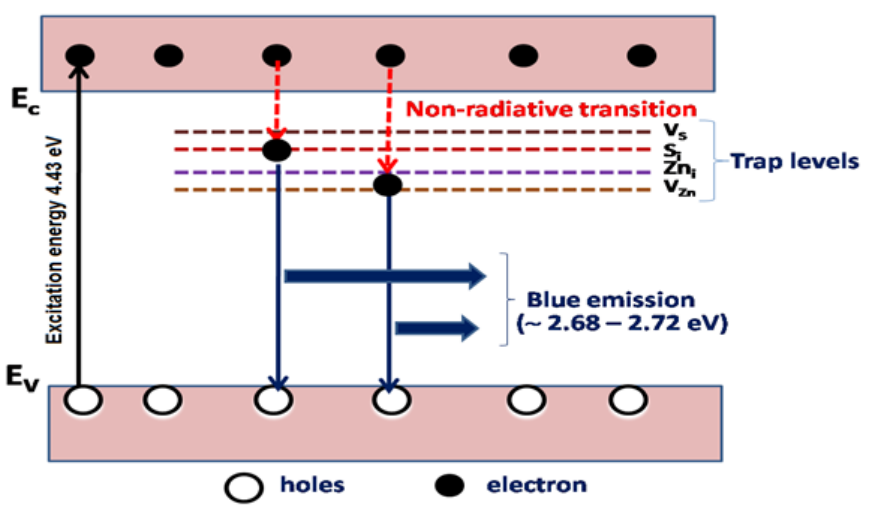

FIG. 10. Energy band diagram of the photoluminescence phenomenon in as-grown ZnS powder grown using different zinc precursors [28]

formation of native defect states. These indicate that anions play a crucial role in defect formation during the growth of thin films.

\subsection{Raman study}

For $514 \mathrm{~nm}$ excitation wavelength, $\mathrm{ZnS}$ thin film has low Raman scattering efficiency and is detectable only with film thickness $1 \mu \mathrm{m}$ or higher [29]. Therefore, the Raman spectra of scratched as-grown ZnS powder (instead of $\mathrm{ZnS}$ thin films) prepared using different zinc precursors were recorded using $514 \mathrm{~nm}$ excitation wavelength (green excitation) shown in Fig. 11. The peak positioned at $348 \mathrm{~cm}^{-1}$ corresponds to the first-order longitudinal optical (LO) mode of $\mathrm{ZnS}$ materials. The second-order and third-order LO modes are observed at 697 and $1018 \mathrm{~cm}^{-1}$, respectively. The obtained results are found consistent with the reviewed literature [29]. The intensity of the LO peak is highest for $\mathrm{ZnS}-\mathrm{Cl}$ and that of the lowest for $\mathrm{ZnS}-\mathrm{SO}$. The peak due to the $2 \mathrm{LO}$ phonon is absent in $\mathrm{ZnS}-\mathrm{SO}$, while a slightly visible peak is observed in $\mathrm{ZnS}-\mathrm{Ac}$ and $\mathrm{ZnS}-\mathrm{Cl}$ with an increase in intensity, respectively. This could be due to anions present in zinc precursors affecting the defect chemistry of $\mathrm{ZnS}$ thin film during deposition, which influences the vibrational mode of $\mathrm{ZnS}$ thin films [29]. The increase in the sharpness of phonon peak represents an improvement in crystallinity [9] which is consistent with the above discussions.

\subsection{Electrical measurements}

The activation energy, electrical resistivity and conductivity of all $\mathrm{ZnS}$ thin films were determined using the twopoint probe method. The relation for resistivity with temperature is denoted by [30]:

$$
\log \rho=\frac{E_{a}}{2.303 \cdot k_{B}}\left(\frac{1}{T}\right)+\log C,
$$




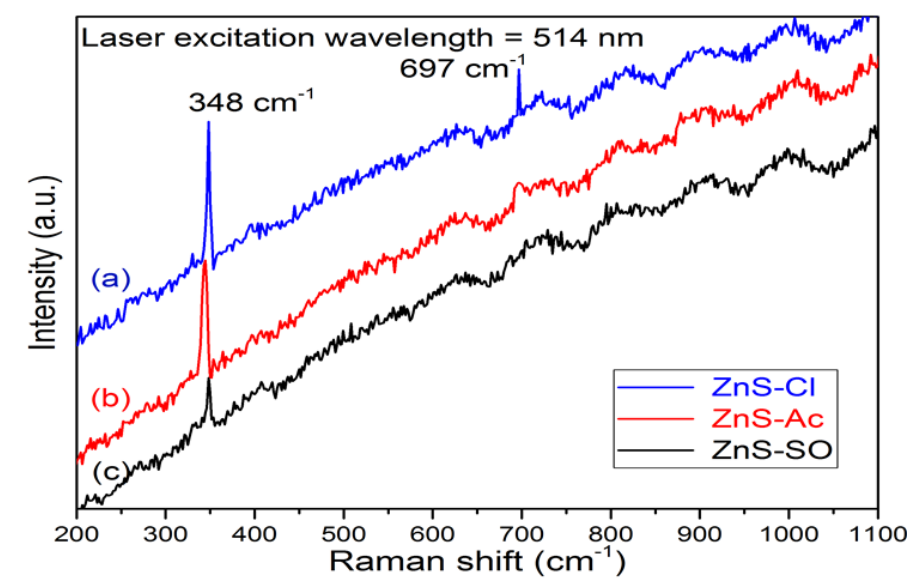

FIG. 11. Raman spectra of as-grown ZnS powders prepared by different zinc precursors: (a) ZnS$\mathrm{Cl}$; (b) ZnS-Ac; (c) ZnS-SO

where $\rho$ is resistivity (in $\Omega \cdot \mathrm{cm}$ ), $E_{a}$ is activation energy (in $\mathrm{eV}$ ), $k_{B}$ is Boltzmann constant (in $\mathrm{eV} / \mathrm{K}$ ), $T$ is the temperature (in Kelvin) and $\log C$ is constant.

The Hall coefficient, carrier concentration and mobility of thin films were figured out using the relation given below [31]:

$$
R_{H}=\frac{V_{H} \cdot t}{I \cdot B}, \quad \eta=\frac{1}{R_{H} \cdot q},
$$

where $R_{H}$ is Hall Coefficient $\left(\mathrm{cm}^{3} / \mathrm{C}\right), V_{H}$ is Hall Voltage (in volt), $I$ is probe current (in Ampere), $t$ is the thickness (in meter), $B$ is the magnetic field (in Gauss) and $\eta$ is carrier concentration (in $1 / \mathrm{cm}^{3}$ ).

The data for the resistivity measurements were recorded by raising the temperature from 35 to $190{ }^{\circ} \mathrm{C}$. The plot for $\log \rho \mathrm{Vs} 1000 / T$ for $\mathrm{ZnS}$ thin film deposited using different zinc precursors is depicted in Fig. 12. The plot of $\log \rho$ versus $1000 / T$ gives a straight line whose slope corresponds to $E_{a} / k_{B}$. The calculated values of resistivity, conductivity and activation energy is represented in Table 4 . The shallow trap levels are responsible for low activation energy $E_{a 1}$ and the deep trap levels are responsible for the high value of activation energy $E_{a 2}$ in the case of $\mathrm{ZnS}-\mathrm{SO}$ thin film [32].

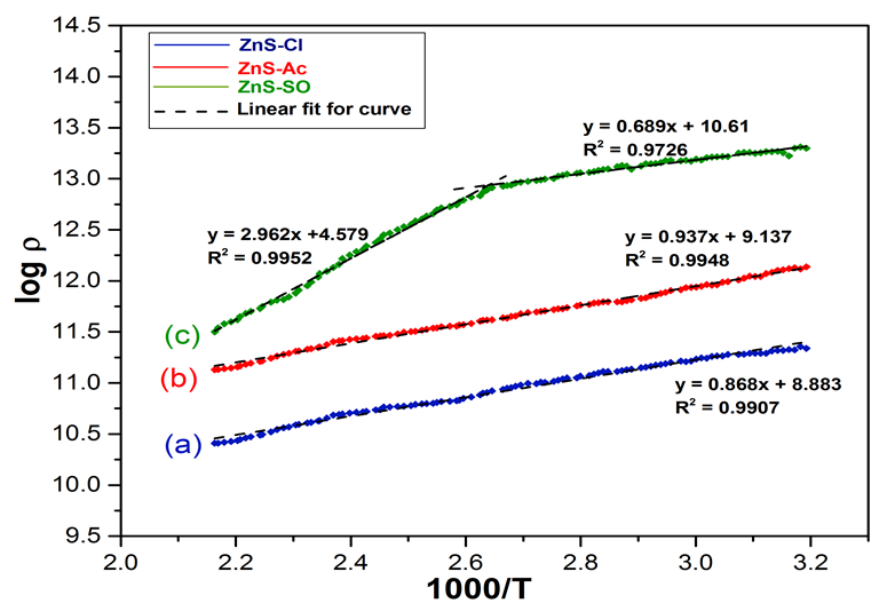

FIG. 12. Plot of $\log \rho$ versus $1000 / T$ for as-grown $\mathrm{ZnS}$ thin films deposited using different zinc precursors

The Hall effect measurements were recorded by keeping probe current constant and varying magnetic field and measuring corresponding Hall voltage. The sketch for Hall voltage versus magnetic field is outlined in Fig. 13. The calculated values for the Hall coefficient, carrier concentration and mobility are listed in Table 4. The n-type conductivity was observed in all $\mathrm{ZnS}$ films irrespective of zinc precursors used. The tabulated values show that $\mathrm{ZnS}-\mathrm{SO}$ thin film has a high charge density and low conductivity compared to other thin films. The explanation of the observed results is that native defect states are generated during the growth of film act as scattering centers 
TABLE 4. Electrical parameter for as-grown $\mathrm{ZnS}$ thin films deposited using different zinc precursors: ZnS-Cl (a); ZnS-Ac (b); ZnS-SO (c)

\begin{tabular}{cccccccc}
\hline \multirow{2}{*}{ Thin film } & \multicolumn{2}{c}{$\begin{array}{c}\text { Activation energy } \\
(\mathbf{e V})\end{array}$} & $\begin{array}{c}\text { Resistivity } \\
\boldsymbol{n}(\boldsymbol{\Omega} \cdot \mathbf{c m})\end{array}$ & $\begin{array}{c}\text { Conductivity } \\
\boldsymbol{\sigma}\left(\boldsymbol{\Omega}^{-1} \cdot \mathbf{c m}^{-1}\right)\end{array}$ & $\begin{array}{c}\text { Hall } \\
\text { Coefficient } \\
\mathbf{R H}\left(\mathbf{c m}^{3} / \mathbf{C}\right)\end{array}$ & $\begin{array}{c}\text { Carrier } \\
\text { concentration } \\
\boldsymbol{\eta}\left(\mathbf{c m}^{-\mathbf{3}}\right)\end{array}$ & $\begin{array}{c}\text { Mobility } \\
\boldsymbol{\mu}\left(\mathbf{c m}^{2} / \boldsymbol{V}_{\boldsymbol{s}}\right)\end{array}$ \\
\hline \hline ZnS-Cl & 0.75 & - & $2.08 \times 10^{4}$ & $4.81 \times 10^{-5}$ & $3.48 \times 10^{3}$ & $1.79 \times 10^{15}$ & $1.68 \times 10^{-1}$ \\
\hline ZnS-Ac & 0.81 & - & $1.63 \times 10^{4}$ & $6.14 \times 10^{-5}$ & $1.71 \times 10^{2}$ & $3.65 \times 10^{16}$ & $1.05 \times 10^{-2}$ \\
\hline ZnS-SO & 0.59 & 2.55 & $8.52 \times 10^{4}$ & $1.17 \times 10^{-5}$ & $2.53 \times 10^{1}$ & $2.47 \times 10^{17}$ & $2.97 \times 10^{-4}$ \\
\hline
\end{tabular}

for conduction electrons in the film.So defect chemistry and hence anions associated with zinc precursors play an important role in the electrical transport properties of $\mathrm{ZnS}$ thin films. Fig. 14 represents the comparative graph for carrier concentration, conductivity and mobility for $\mathrm{ZnS}$ thin films. It reveals from the graph that $\mathrm{ZnS}-\mathrm{Cl}$ shows a considerable amount of conductivity compared to other samples even though its low carrier concentration. This is due to the high mobility offered by it.

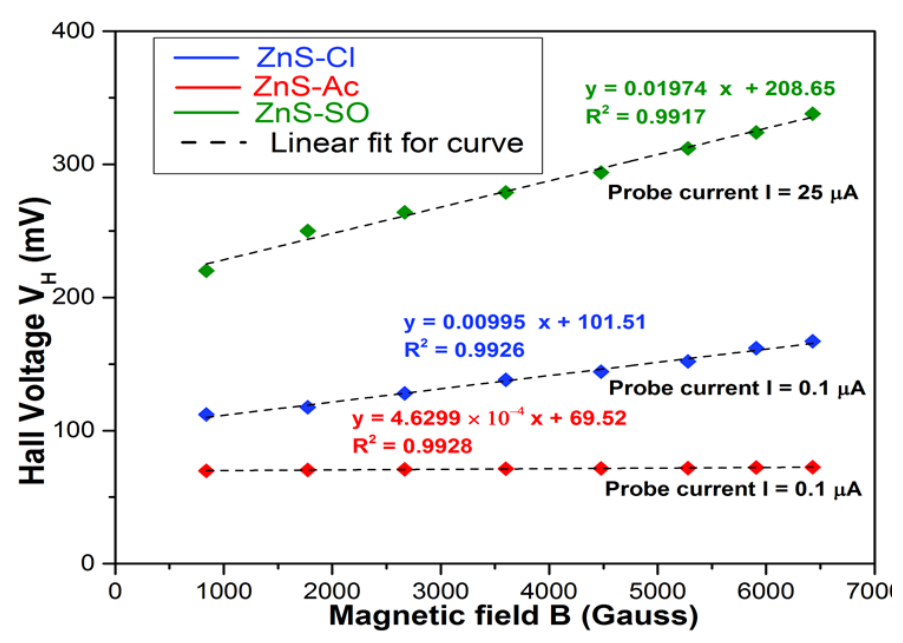

FIG. 13. Plot of Hall voltage VH versus magnetic field B for constant probe current of $\mathrm{ZnS}$ thin films deposited using different zinc precursors

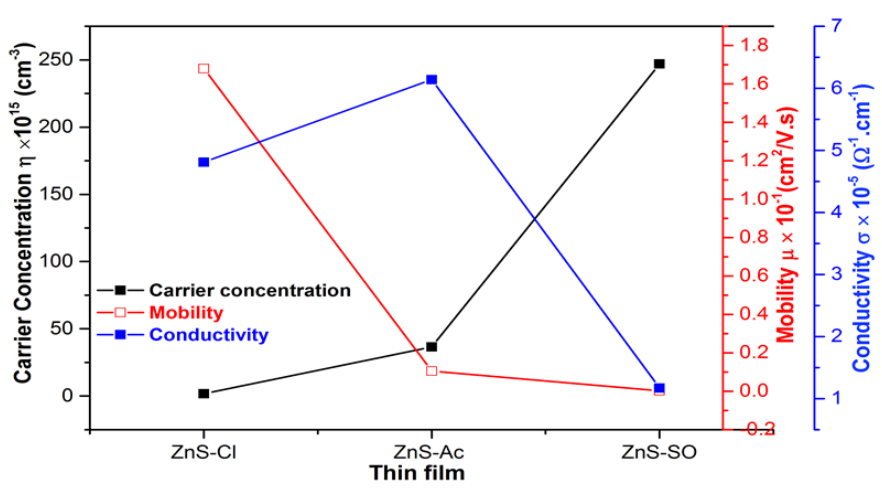

FIG. 14. Comparative graph for carrier concentration, mobility and conductivity for as-grown $\mathrm{ZnS}$ thin films deposited using different zinc precursors 


\section{Conclusion}

Good quality ZnS thin films have been deposited onto silica substrates using different zinc precursors, thiourea, non-toxic complexing agent triethanolamine (TEA) by optimizing bath parameters. The XRD confirms the hexagonal phase with maximum intensity peak along ( $\left.\begin{array}{lll}0 & 0 & 10\end{array}\right)$ plane of as-grown $\mathrm{ZnS}$ thin film prepared using different zinc precursors. SEM demonstrates the notable effect of anions of zinc precursors on the growth mechanism of $\mathrm{ZnS}$ thin film. Optical measurements demonstrate transmittance varies from 10 to $29 \%$ in the visible region. The band gap increases with a decrease in particle size due to the quantum size effect. The $\mathrm{ZnS}$ thin film has higher band gap values than the counter bulk sample in the range of $4.10-4.25 \mathrm{eV}$. The blue emission at $\sim 459 \mathrm{~nm}$ was obtained by PL spectra under UV excitation. The first-order Raman shift was observed at $348 \mathrm{~cm}^{-1}$ in all ZnS films. The Hall-effect apparatus measures carrier concentration of order $10^{15}$ to $10^{17} \mathrm{e}^{-} / \mathrm{cm}^{3}$, reflecting the semiconducting nature of ZnS thin film with n-type conductivity. The observed studies show the significant effect of zinc precursors on the transport properties of CBD-ZnS thin films. $\mathrm{ZnS}$ thin film deposited using $\mathrm{ZnCl}_{2}$ as precursor material is found to have good carrier mobility amongst all films.

\section{Acknowledgements}

The authors are grateful to Prof. M. P. Deshpande, Prof. G. K. Solanki and Prof. S. H. Chaki, Department of Physics, Sardar Patel University, VallabhVidhyanagar, Anand, Gujarat for providing TGA, PL and Raman facilities. We also acknowledge IISER, Bhopal for XRD Study. We also extend our thanks to the Sophisticated Instrumentation Centre for Applied Research \& Testing (SICART), Vallabh Vidhyanagar, Gujarat for UV/Visible measurements and Charotar University of Science and Technology (CHARUSAT), Changa, Gujarat for SEM.

\section{References}

[1] Nemade K.R., Waghley S.A. Ultra-violet C absorption and LPG sensing study of zinc sulphide nanoparticles deposited by a flame-assisted spray pyrolysis method. Journal of Taibah University for Science, 2016, 10 (3), P. 437-441.

[2] Islam M.M., Ishizuka S., et al. CIGS solar cell with MBE-grown ZnS buffer layer. Solar Energy Materials \& Solar Cells, 2009,93 , P. $970-972$.

[3] Bujňáková Z., Dutková E. Mechanochemistry of Chitosan-Coated Zinc Sulphide (ZnS) Nanocrystals for Bio-imaging Applications. Nanoscale Research Letters, 2017, 12, 328.

[4] Ben Nasr T., Kamoun N., Guasch C. Structure, surface composition, and electronic properties of zinc sulphide thin films. Materials Chemistry and Physics, 2006, 96, P. 84-89.

[5] Ubale A.U., Kulkarni D.K. Preparation and study of thickness dependent electrical characteristics of zinc sulfide thin films. Bull. Mater. Sci., 2005, 28 (1), P. 43-47.

[6] Yu F-P., Ou S-L., et al. Structural, Surface Morphology and Optical Properties of ZnS Films by Chemical Bath Deposition at Various Zn/S Molar Ratios. Journal of Nanomaterials, 2014, 6, P. 1-7.

[7] Gode F. Annealing temperature effect on the structural, optical and electrical properties of ZnS thin films. Physica B, 2011, 406, P. 1653-1659.

[8] Zein R., Alghoraibi I. Influence of Bath Temperature and Deposition Time on Topographical and Optical Properties of Nanoparticles ZnS Thin Films Synthesized by a Chemical Bath Deposition Method. Journal of Nanomaterials, 2019, 1-13.

[9] Cao M., Zhang B.L., Li L. Huang J., et al. Effects of zinc salts on structural and optical properties of acidic chemical bath deposited ZnS thin films. Materials Research Bulletin, 2013, 48, P. 357-361.

[10] Liu T., Ke H., et al. Effect of four different zinc salts and annealing treatment on growth, structural, mechanical and optical properties of nanocrystalline ZnS thin films by chemical bath deposition. Materials Science in Semiconductor Processing, 2014, 26, P. 301-311.

[11] Gurin N.T., Sabitov O.Y., Afanas'ev A.M. Characteristics of surface states at the insulator-semiconductor interface in the thin-film electroluminescent structures based on ZnS:Mn. Semiconductors, 2010, 44 (4), P. 498-507.

[12] Migita M., Kanehisa O., Shiiki M. Yamamoto H. The Preparation of ZnS:Mn electroluminescent layers by MOCVD using new manganese sources. Journal of Crystals Growth, 1988, 93 (1-4), P. 686-691.

[13] Lindroos S., Kanniainen T. Leskela M., Rauhala E. Deposition of manganese-doped zinc sulfide thin films by the successive ionic layer adsorption and reaction (SILAR) method. Thin Solid Films, 1995, 263 (1), P. 79-84.

[14] Doña J. M., Herrero J. Process and film characterization of chemical-bath-deposited ZnS thin films. Journal of The Electrochemical Society, 1994, 141 (1), P. 205-210.

[15] Oladeji I.O., Chow L., et al. Comparative study of CdS thin films deposited by single, contineous, and multiple dip chemical processes. Thin Solid Films, 2000, 359 (2), P. 154-159.

[16] Liu J., Wei A., Zhao Y. Effect of different complexing agents on the properties of chemical-bath-deposited ZnS thin films. Journal of Alloys and Compounds, 2014, 588, P. 228-234.

[17] Khatri R.P., Patel A.J. Effect of post annealing on CBD deposited ZnS thin films. International Journal of Scientific Research and Reviews, 2018, 7 (1), P. 374-384.

[18] Basha S.J., Khidhirbrahmendra V., et al. Structural, optical, magnetic and thermal investigations on Cr3+ ions doped ZnS nanocrystals by co-precipitation method. Journal of Science: Advanced Materials and Devices, 2019, 4, P. 260-266.

[19] Cullity B.D., Stock S.R. Element of X-ray Diffraction, Addison-Wesley, Massachusetts, 1956, 99 p.

[20] Wang J., Hou S., et al. Ultra-rapid formation of $\mathrm{ZnO}$ hierarchical structures from dilution-induced supersaturated solutions. Cryst. Eng. Comm., 2014, 16, P. 7115-7123.

[21] The Materials Project. Materials Data on $\mathrm{Zn}(\mathrm{HO})_{2}$ by Materials Project. United States, 2020. URL: https://doi.org/10.17188/1278479. 
[22] Echendu O.K., Weerasinghe A.R., et al. Characterization of n-type and p-type ZnS thin layers grown by an electrochemical method. Journal of Electronic Materials, 2013, 42 (4), P. 692-700.

[23] Moholkar A.V., Agawane G.L., et al. Influence of deposition temperature on morphological, optical, electrical and opto-electrical properties of highly textured nano-crystalline spray deposited CdO:Ga thin films. Applied Surface Science, 2010,257 (1), P. $93-101$.

[24] Ruffner J.A., Himel M.D., et al. Effects of low substrate temperature and ion assisted deposition on composition, optical properties, and stress of ZnS thin films. Applied Optics, 1989, 28 (24), 5209.

[25] Ahn H., Um Y. Post-annealing effects on ZnS thin films grown by using CBD method. Journal of Korean Physical Society, 2015 , 67 (6), P. $1045-1050$

[26] Nadeem M.Y., Ahmed W. Optical properties of ZnS thin films. Turk. J. Phy., 2000, 24, P. 651-659.

[27] Mendil R., Ben Ayadi Z., Ben Belgacem J., Djessas K. The properties of ZnS thin films prepared by rf-magnetron sputtering from nanoparticles synthesized by solvothermal/hydrothermal route. J. Mater. Sci.: Mater. Electron., 2016, 27, P. 444-451.

[28] Babu P., Reddy M., et al. Chemical bath deposition of Mn-doped ZnS thin films using greener complexing agents: Effect of Mn-doping on the optical properties. Optik, 2017, 130, P. 608-618.

[29] Fairbrother A., Izquierdo-Roca V., et al. ZnS grain size effects on near-resonant Raman scattering: optical non-destructive grain size estimation. Cryst. Eng. Comm., 2014, 16, P. 4120-4125.

[30] Vishwakarma R. Effect of substrate temperature on ZnS films prepared by thermal evaporation technique. J. Theor. Appl. Phys., 2015, 9, P. 185-192.

[31] Shukla V., Patel A. Effect of doping concentration on optical and electrical properties of intrinsic n-type $\mathrm{ZnO}$ (i- $\mathrm{ZnO}$ ) and (Cu,Na and K) doped p-type ZnO thin films grown by chemical bath deposition method. Nanosystems: physics, chemistry, mathematıcs, 2020 , 11 (4), P. $391-400$.

[32] Göde F., Gümüş C. Influences of copper and manganese concentrations on the properties of polycrystalline $\mathrm{ZnS}: \mathrm{Cu}$ and $\mathrm{ZnS}: \mathrm{Mn}$ thin films. Journal of Optoelectronics and Advanced Materials, 2009, 11 (4), P. 429-436. 